\title{
Research on the Technology Economic Comprehensive Evaluation and Development Strategy of New Energy Vehicle
}

\author{
Peng Zhang ${ }^{1, a}$, Xiaoping Tang ${ }^{1, b}$ and Li Guo ${ }^{1, \mathrm{c}, *}$ \\ ${ }^{1}$ Department of Driver Training Service, Bengbu Automobile NCO Academy, Bengbu 233011, Anhui \\ azp-right@163.com, ${ }^{\mathrm{b}}$ Tang_xp@163.com, *,c290503157@qq.com
}

Keywords: New Energy Vehicle, Technology, Economic, Comprehensive Evaluation, Development Strategy

\begin{abstract}
In recent years, as China's economy continues to develop and progress, our country is facing with increasingly serious energy tense situation. Through the actual survey we found that the prices of international crude oil continue to rise. Meanwhile, the people's living standards continue to improve, people's quality of life and working environment have become increasingly demanding and their environmental awareness is gradually increased. In such cases, the degree of people pay attention to the new energy vehicle technology is increasing and particularly for the current development of China's new energy vehicle technology China's relevant departments continue to carry out in-depth study on technology research and industrial development of new energy vehicles. We need to establish and improve the new economic appraisal system of energy vehicles and clearly our specific strategic direction of new energy vehicles.
\end{abstract}

\section{Introduction}

With the continuous progress of the times, people's understanding of new energy sources more comprehensive, but also improve on the importance of new energy vehicles. On the current level of development of new energy and the actual situation, the new energy vehicle technology itself has a unique advantage. Development of new energy vehicle technology, not only help solve the shortage of petroleum resources, but also conducive to energy conservation, ensuring energy security. The emergence of new energy in large part to ease the supply and demand of oil, continue to adjust the structure of the automobile industry. In severe impact of the financial crisis, the development of new energy sources has become an important way to sustainable development. Meanwhile, the development of new energy sources has also contributed to the rapid development of a large number of related industries. In recent years, the world's major automobile-producing countries have to develop new energy as an important sustainable and healthy development of national measures, will enhance industrial competitiveness as an important measure. Especially since 2010, there have been with the hybrid car-based new energy automotive industry climax. For China's auto industry, the development of new energy vehicle technology will have important significance. New energy vehicle technology will become the main direction of the automobile industry has become an important measure of market economy. Application of new energy vehicle technology, help to optimize the structure of the automobile industry, constantly promote China's auto industry leaps and bounds, which is a necessary condition for the construction of "two-oriented society".

\section{The Technical Evaluation of New Energy Vehicles}

New energy vehicles in terms relative to the traditional fuel vehicles, usually new energy vehicles, also known as alternative fuel vehicles. As the economy continues to develop, resulting in a gradual reduction of energy, energy supply problem has become a hot topic of global concern, it is our country's oil resources, for example, is not rich in oil resources, according to the survey, total oil resources in the whole consumption, transportation and energy consumption have an enormous proportion of oil resources will soon become the most serious energy problems facing our country. During the use of petroleum resources, transportation and energy consumption will seriously affect the environment, and a large number of global greenhouse gas emissions. Based on this grim energy 
situation, the development of new energy car technology is imperative, so that China achieve transformation transport energy power systems [1].

Evaluation of Hybrid Cars. After the existing energy comprehensive understanding and study, which can become alternative energy new energy vehicles are: gas fuel, biomass-based liquid hydrogen fuel, electric power, nuclear energy. Commonly known as hybrid vehicles, mainly refers not simply to provide the use of an energy converter drive vehicle, such a vehicle is called hybrid electric vehicles. Under normal circumstances, hybrid cars divided into different categories, including: series hybrid cars and parallel hybrid cars, hybrid-type vehicles. The emergence of the hybrid vehicle with an internal combustion engine and electric vehicles have a direct relationship, in a sense, hybrid electric vehicles and is divided into two, namely gasoline hybrid and diesel hybrid, but the two key technologies are mixed power system.

Advantage hybrid which can also be to a gas station, car habits have not changed; the government and enterprises to promote this product there is no need to invest in new equipment or charging higher economic performance of its fuel stations, and which has superior commission with nature, in the start-up and acceleration, the electric motor can assist, this will greatly reduce fuel consumption, and ultimately l, zero l, discharge; in addition, the use of the motor work, largely reducing the mechanical noise. Hybrid cars disadvantages: it is not mature in technology, higher pricing related products, high cost of electric motor and internal combustion engines cost of two power systems than a power system if the long high-speed or constant speed without fuel.

Evaluation of Pure Electric Vehicles. Pure electric vehicles will mainly vehicle power supply as the main driving force in the pure electric vehicles, there is no combustion engine launch devices. Pure electric car itself has unique advantages, mainly no pollution, low noise, high efficiency, once a pure electric car fails, its service more convenient and simple.

Technical Evaluation of Other Types of Vehicles. NGV mainly to natural gas as a fuel, because our commission has abundant natural gas resources, which greatly promoted the rapid development of natural gas vehicle technology is mainly hydrogen engine car adapted from the basis of existing engines, hydrogen engine car There is no pollution. Less their emissions, while the lower requirements for hydrogen, the most important advantage is that the internal combustion engine technology is relatively mature; the development of new energy vehicle technology is in a bottleneck, which requires a gradual improvement in technology patents, facilities and other leavened dough and development, which requires the relevant professional departments of the new energy vehicles in-depth study [2].

\section{The Economic Evaluation of New Energy Vehicles}

The Economic Evaluation of New Energy Vehicles. New energy vehicles mainly to a more standardized fuel as a primary power source, its high energy requirements, including: high energy density of energy, less polluting energy, to focus on energy production and use of cost economy and make the greatest trying to keep a good performance. Only in such conditions can we promote the rapid development of new energy technologies. New energy technologies has begun to implement in many areas, in the implementation process has been very good feedback. Under the current technical conditions, the development of new energy vehicle technology has provided long-term economic interests for the majority of consumers and society. Its use not only played their high cleanliness, but also effectively improved the economic performance. Conducting new energy technology research, and continue to emphasize the use of the various components and service life.

The Economic Evaluation of Hybrid Cars. For hybrid vehicles, which the commission has two drive ways, namely fuel type and power type. Technical indicators system of hybrid vehicles including five that price, displacement, saving rate, sales of five parts, the five technical indicator system capable of hybrid vehicles overall economic performance and reflect the situation. Where sales mainly reflects market demand for hybrid cars, if the sales volume is good, indicating that the market demand for hybrid vehicles, the market demand for higher levels if sales is low, less market demand clearly shows a hybrid vehicle, the low level of market demand. Saving rate is mainly based on hybrid vehicles compared with ordinary cars above, hybrid vehicles save fuel ratio, the 
saving rate depends largely on the hybrid vehicle electric drive technology, with a strong technology higher saving rate of hybrid cars [3].

\section{The Comprehensive Evaluation of New Energy Vehicles}

Comprehensive Evaluation System for new energy vehicles, at the same level indicator system, allowed a significant containment. Design of new energy comprehensive evaluation system with strict requirements, the specific circumstances of international science and technology from the current trends were to consider the design of its index system to meet the current situation of major international science and technology development and to meet the requirements of the times. When selecting indicators, to focus on the object of summary evaluation common features, to make the selected indicators in line with the overall characteristics of the evaluation object, consider quantitative evaluation should focus on the feasibility, and whether the index data can be obtained.

When the new energy automobiles systematic comprehensive evaluation, not only to pay attention to energy-saving cars problem, but also attention to the selection of principle new energy technologies and products. The status quo of the current national automotive industry to conduct a comprehensive and integrated analysis, the new energy vehicle technology is conducive to environmental protection and safety, on national realities energy situation and environmental conditions, the new energy vehicle technology is an important development strategy. Which has industrial base standards for energy conservation has significant guiding devices and the corresponding sensor on the composition of the electro-hydraulic steering system EHPS. If installed between the upstream guide sensor, two cars traveling at high speed and can be compared between rows farming when high accuracy if the car is equipped with two global positioning system DGPS, you can make the car two meters below the rank of positioning to centimeter level even. Automatic steering. DongZL such as the use of electro-hydraulic proportional valve constitute automatic steering system, and each of the three PID control algorithm with nonlinear compensation were compared [4].

Japan 's Department of Biology, promote specific industry technology research institutions "from 1993 began to study robotics and unmanned sprayer arable land, the development of vegetables, fruit trees with sprayers, by detecting buried there through the magnetic field generated by the AC cable walking boot of the vehicle, carry out spraying operations, spraying speed $0 . \mathrm{sm} / \mathrm{s}$, seen from the experimental test having practicability.

\section{The Development Strategy of New Energy Vehicle}

The Government Increases the Financial Support for New Energy Cars. New energy vehicle development requires a lot of new technical support, but also inseparable from financial support, governments are the development of new energy vehicles provide a lot of support, whether it is human, material, technical or economic, it is to promote new energy automotive industry developing essential. Government financial support mainly through financial subsidies, tax incentives and also supports the development of the industrial system, such as: providing a charging device car needed new energy in the building housing, promoting collaboration in different fields. In addition to the new energy automobile development, production and financial support, but also can give convenient in terms of sales, such as: reduction of the consumption tax, cash subsidies, while actively increase environmental protection efforts of low-carbon travel, so that more low-carbon form motorist Civilization consumption habits.

Seek New Energy Vehicle Technology Cooperation. An important way to promote new energy vehicle development is to improve the technical strength, in particular, should start their own technological capabilities, from the United States, Europe, Japan and other new energy automotive advanced technology experience, with the international arena, to achieve a new energy vehicle technology research and development. It can also establish transnational collaborative $\mathrm{R} \& \mathrm{D}$ institutions, public innovation and research of new energy vehicle technology, or the use of 
international technological achievements, participation in international organizations new energy automotive industry [5].

Accelerate the Development of the Industrial System Model. New energy vehicles as the main direction of the future development of the automotive industry, in order to promote the expansion of industrial scale, we must promote the development of the construction industry system. New energy automotive industry alliance is a typical industrial system, through further improvement can really form a new energy automotive system development model, where the need to support a large number of new technologies, from vehicle development to production are carried out supporting, in the promotion of new energy At the same time development of the automotive industry, but also led to the development of new energy technologies.

The Implementation of the New Energy Vehicle Development Strategy. For the actual situation of China's new energy vehicle development, in order to continuously improve the new energy vehicle development technology, to establish and improve the "business-led, government-led" development model. Select the appropriate technology on the basis of the above routes, focusing on major technology and components independent research work, the government vigorously promote independent research and development, due to increase R \& D funding, and independent research and development and technology integration. Direct economic benefits continue to implement the introduction of technology, professional sterile walls of new energy R \& D personnel, thereby enhancing new energy vehicle technology.

The Implementation of New Energy Automotive Industry Policy. To develop scientific and rational planning industry, adding new energy to market demand, continue to strengthen cooperation between industry and industry. Increase infrastructure construction, highlighting the importance of supporting industries and continue to develop supporting industries.

The Implementation of Brand Strategy of New Energy Vehicles. Focus on the development of its own brand of new energy vehicles, new energy vehicles, strengthen the continuous extension of the brand, and vigorously promote the new energy automotive brands. By multinational auto companies can improve the competitiveness of brand products, so you can beneficial new energy automobile brand promotion, thus the formation of more familiar brand new energy vehicles.

\section{Conclusions}

In the background of growing energy shortage and environmental pollution, new energy vehicles has become an inevitable trend. In order to accelerate the development of new energy vehicles, from the economic and technical aspects, strive to replace ordinary cars with the new energy vehicles to get rid of energy shortages limit.

\section{References}

[1] Xianjing Ruan: Journal of Wuhan Technology University, Vol. 10 (2010) No 53, p.67-69

[2] Yunlong Xuan: Scientific Management Research, Vol. 12 (2005) No 27, p.74-76

[3] Jing Zhang: North China Water Resources and Hydropower Institute, Vol. 11 (2010) No 33, p.11-14

[4] Qingyu Liu: North China Electric Power University, Vol. 3 (2007) No33, p.121-124

[5] Lanjian Liu: Scientific Management Research, Vol. 18 (2010) No 35, p.45-52 